\author{
마이크로파조사를 위한 개질화 활성탄의 톨루엔 탈착 \\ 최성우 · 추헌직 \\ 계명대학교 환경과학 \\ (2010년 10월 28일 접수; 2010년 11월 26일 수정; 2011년 1월 5일 채택)
}

\title{
Toluene Desorption of Modified Activated Carbon for Microwave Irradiation
}

\author{
Sung-Woo Choi ${ }^{*}$, Heon-Jik Chu \\ Department of Environmental Science and Engineering, Keimyung University, Daegu 704-701, Korea \\ (Manuscript received 28 Octover, 2010; revised 26 November, 2010; accepted 5 January, 2011)
}

\begin{abstract}
Toluene desorption of modified activated carbon for microwave irradiation was evaluated. As a virgin GAC reacted from microwave energy, it created an "arcing" between GAC particles in desorption process. The arcing became more and more vigorous and achieved a red flame of GAC. The silica coated $\mathrm{GAC}(\mathrm{Si} / \mathrm{GAC})$ was developed to prevent arcing phenomenon and temperature control problem. The result shows virgin GAC with $5 \mathrm{wt} \%, 10 \mathrm{wt} \%$ and $20 \mathrm{wt} \%$ silica had no arcing and could control temperature very well. However, the adsorption rate of $\mathrm{Si} / \mathrm{GAC}$ was decreased by coated silica amount due to decreasing surface area of GAC. The $5 \mathrm{wt} \% \mathrm{Si} / \mathrm{GAC}$ adsorption rate was quite similar to virgin GAC adsorption rate. After adsorption, the toluene-loaded $\mathrm{GAC}$ and $\mathrm{Si} / \mathrm{GAC}$ was reactivated by $2450 \mathrm{MHz} \mathrm{MW}$ irradiation with $300 \mathrm{~W}$ for 5 min. Quantitative desorption of the toluene was achieved at MW irradiation at $300 \mathrm{~W}$ with desorption efficiencies as high as $98.59 \%$ to $84.65 \% \%$ after four cycles.
\end{abstract}

Key Words : Microwave, Desorption, Si/GAC, GAC

\section{1. 서 론}

톨루엔은 대표적인 휘발성유기화합물로 인체유해 물질로 분류되어 있으며, 이를 저감하기 위한 다양한 기술이 개발되고 있다. 그 중 활성탄을 이용한 흡착 방 법은 대표적인 저감방법으로 잘 알려져 있다(임 등, 2003). 그러나 활성탄을 이용한 흡착방법은 흡착제의 재생에 어려움이 있어, 대부분 폐기 되고 일부는 재생

Corresponding author : Sung-Woo Choi, Department of Environmental Science, Keimyung University, Daegu 704-701, Korea

Phone: +82-53-580-5245

E-mail: swchoi@kmu.ac.kr
하여 재이용 되고 있으나 재사용비율은 그리 높지 않 다(류 등, 1998). 현재 활성탄 재생 및 탈착에 관한 연구가 지속적으로 진행되고 있으며, 그 중 열적, 화 학적, 생물학적 재생방법이 가장 많이 사용되고 있는 기술이다(Lim과 Okada, 2005). 이러한 기술을 바탕으 로 Misra 등(2002)은 공기와 수증기가 혼합된 기체를 이용하여 trinitrotoluene, nitrobenzene이 흡착된 폐활 성탄을 열적 탈착을 이용하여 활성탄을 재생하였고, Alvarez 등(2004)은 페놀이 흡착된 활성탄을 열적으 로 재생하였다. 또한, Horng 등(2008)은 자외선 조건 하에서 과산화수소를 이용하여 아세톤과 이소프로필 알코올이 흡착된 활성탄을 화학적으로 재생하였으며, Aktas 등(2007)은 2-Chlorophenol이 흡착된 활성탄을 
생물학적 방법을 이용하여 탈착 후 재생하였다. 하지만 이들은 공정의 복잡성과 긴 재생시간에 단점을 가지고 있어 이를 대체하려는 연구가 활발히 진행되고 있다.

최근 마이크로파의 기술을 이용하여 Varma 등 (2003)은 유기합성, Zong 등(2002)은 중합체 합성, Perez-Cid 등(2001)은 하수 슬러지 내 금속물질의 분 리, $\mathrm{Lu}$ 등(2003)은 분석화학 등 마이크로파의 활용 영 역이 점차 확대 되고 있다. 뿐만 아니라 마이크로파를 이용하여 Ania 등(2005)은 페놀, Liu 등(2007)은 2,4,5-Trichlorobiphenyl, Kong 등(1995)은 질소산화 물, Fang 등(1996)은 에탄올과 아세톤이 흡착된 활성 탄의 탈착 및 재생에 관한 연구를 발표하고 있다. 그러 나 Jou 등(1998)은 활성탄과 같이 탄소계 물질들은 마 이크로파 조사 시 "boiled off" 된 유리전자가 형성 되 어 유리전자는 활성탄입자 사이에서 발생되는 전위차 에 의해 아크방전을 야기 시키고, 이는 활성탄의 물리 적 구조를 변형 시킬 우려가 높다고 보고하였다.

따라서 본 연구는 톨루엔이 흡착된 활성탄의 재생 에 관한 기초연구로 마이크로파를 이용하여 톨루엔의 탈착에 관한 연구를 수행하였다. 탄소계 물질에 마이 크로파 조사 시 발생되는 아크방전현상을 방지하기 위해 절연물질인 규석분말을 활성탄 표면에 코팅을 하여 방전현상 및 온도변화를 확인하였다. 또한 규석 분말 코팅에 따른 흡착효율의 변화량 및 표면분석을 실시하였으며, 마이크로파 조사에 따른 탈착효율 및 내구성평가를 통해 마이크로파에 가장 적합한 탄소계 흡착제를 개발하고자 하였다.

\section{2. 재료 및 방법}

\section{1. 연구재료 및 시약}

본 연구에 사용된 흡착제는 일본 D사(XL-7100)의 구형 활성탄(granular active carbon : GAC)을 사용하 였고, 인산 $10 \%$ 를 증류수에 혼합하여 24시간동안 담 근 후 표면에 침착된 불순물을 제거하여, 오븐에서 $110^{\circ} \mathrm{C}$ 에서 항량건조 하였다. 또한 20-40 mesh의 미세 분말 규석을 $\mathrm{GAC}$ 와 무게 비율로 $5 \mathrm{wt} \%, 10 \mathrm{wt} \%$, $20 \mathrm{wt} \%$ 로 각각 구분하여 무기바인더와 $\mathrm{KOH}$ 을 질량 비를 $1: 1$ 로 $25 \mathrm{ml}$ 의 증류수에서 $50^{\circ} \mathrm{C}, 1$ 시간 교반 시 킨 후, 회전식 조류기를 이용하여 스프레이 분사를 통
하여 $\mathrm{GAC}$ 를 코팅하였으며 $\mathrm{Si} / \mathrm{GAC}$ 로 명명 하였다. 또한 흡착실험에 사용될 피흡착질은 DUKSAN사의 순도 $99.5 \%$ 톨루엔을 사용하였다.

\section{2. 연구방법}

톨루엔의 흡착실험은 미국 Brooks사의 $5850 \mathrm{E}$ series의 질량유량조절기(MFC)를 이용해 희석가스인 질소 $150 \mathrm{ml} / \mathrm{min}$ 과 톨루엔 $50 \mathrm{ml} / \mathrm{min}$ 을 혼합하여 반 응기로 유도 했으며, 상온에서 GAC $1 \mathrm{~g}$ 이 충진 된 반 응기에 톨루엔을 흡착시켜 Hewlett Packard model 6890 의 GC-FID로 분석 하였다.

톨루엔의 탈착 실험을 위한 마이크로파 발생장치 는 최대출력 $2 \mathrm{~kW}$, 주파수 $2450 \pm 50 \mathrm{MHz}$ 의 마그네트 론을 사용하였고, 반응장치는 유전 손실이 낮은 내경 $8 \mathrm{~mm}$ 의 석영제 U자 반응기를 사용하였다. 반응기 내 부온도를 측정하기 위해 k-type thermalcouple를 설치 하였고, 방전 측정은 일본 Hamamatsu사의 photosensor module H5784-03 방전센서와 digital real time oscilloscope로 방전피크를 확인하였다. 또한 $\mathrm{CE}$ 사의 mettler toledo AB204-S의 digital balance를 이용해 흡착 및 탈착 전후 무게를 비교 하였다.

\section{3. 결과 및 고찰}

\section{1. 표면분석}

일반 $\mathrm{GAC}$ 와 규석으로 코팅 된 $\mathrm{GAC}$ 의 표면 침착 형태를 확인하기 위해 전기오븐 $110^{\circ} \mathrm{C}$ 에서 24 시간 이 상 항량건조 된 시료를 일본 Hitachi사의 S-4200 주사 전자현미경(scanning electron microscopy : SEM)을 이용하여 Fig. 1 에 나타내었다. Fig. 1에서 볼 수 있듯 이 활성탄의 공극형태가 규소의 코딩함량별로 약간의 차이를 보이나 이는 활성탄의 불규칙적인 공극크기에 따른 것으로 사료되며 일반 $\mathrm{GAC}$ 의 경우 표면이 비교 적 깨끗하나 규석으로 코팅된 $\mathrm{GAC}$ 는 규석의 함량이 증가함에 따라 표면에 규석 입자가 불규칙하게 증가 된 양상을 보여주었다. 또한 비표면적의 변화량을 관 찰하기위해 $\mathrm{BET}$ (brunauer- emmett-teller)분석하여 Table 1에 나타내었다. BET분석결과를 살펴보면 일 반 $\mathrm{GAC}$ 의 표면적을 1로 보았을 때 $5 \mathrm{wt} \% \mathrm{Si} / \mathrm{GAC}$ 는 $0.87,10 \mathrm{wt} \% \mathrm{Si} / \mathrm{GAC}$ 는 $0.72,20 \mathrm{wt} \% \mathrm{Si} / \mathrm{GAC}$ 는 0.67 


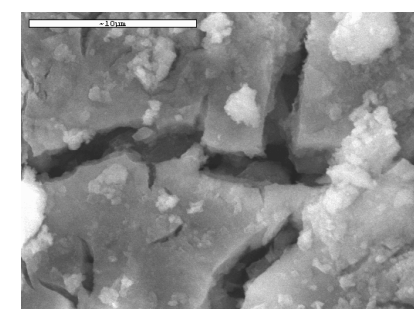

(A)

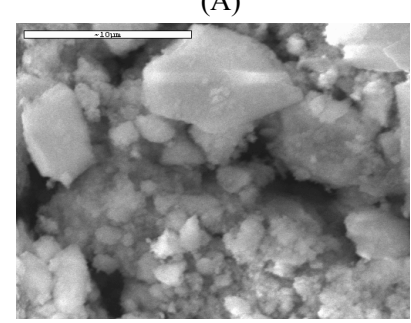

(C)

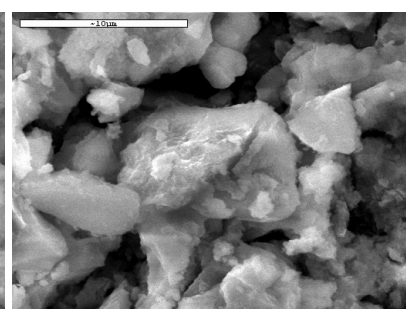

(B)

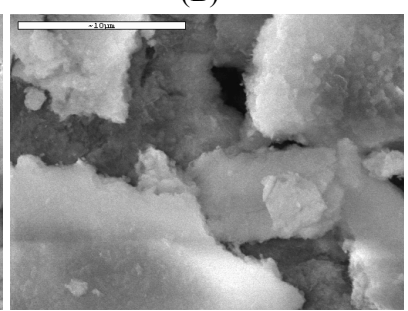

(D)

Fig. 1. SEM images of materials (A : Virgin GAC, B : $5 \mathrm{wt} \% \mathrm{Si} / \mathrm{GAC}, \mathrm{C}: 10 \mathrm{wt} \% \mathrm{Si} / \mathrm{GAC}, \mathrm{D}: 20 \mathrm{wt} \% \mathrm{Si} / \mathrm{GAC}$ ).

의 비율로 규소함량이 증가함에 따라 비표면적이 $13 \%$ 에서 $33 \%$ 까지 감소함을 알 수 있었다. 규소코팅 에 의한 활성탄의 비표면적 감소는 톨루엔 흡착에 영 향을 줄 것으로 사료되나 톨루엔의 열적탈착을 위해 사용되는 마이크로파를 $\mathrm{Si} / \mathrm{GAC}$ 에 조사할 경우 아크 방전을 줄여 탈착온도 조절이 용이할 것으로 사료 된다.

Table 1. Specific surface area of materials

\begin{tabular}{cc}
\hline Materials & Specific surface area $\left(\mathrm{m}^{2} / \mathrm{g}\right)$ \\
\hline \hline Virgin GAC & 1015.4146 \\
$5 \mathrm{wt} \% \mathrm{Si} / \mathrm{GAC}$ & 885.7903 \\
$10 \mathrm{wt} \% \mathrm{Si} / \mathrm{GAC}$ & 732.2826 \\
$20 \mathrm{wt} \% \mathrm{Si} / \mathrm{GAC}$ & 685.1518 \\
\hline
\end{tabular}

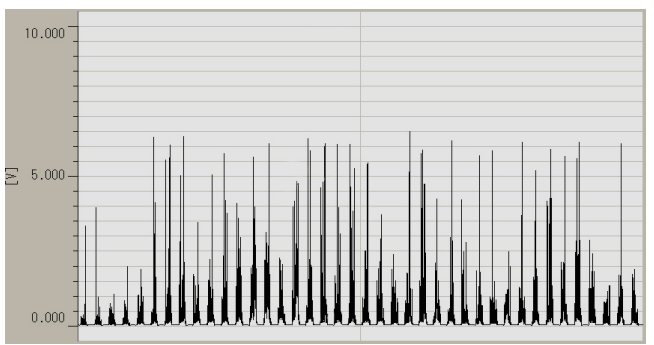

(A)

\section{2. 마이크로파 조사에 따른 방전 및 온도 변화}

활성탄과 같이 탄소계 물질에 마이크로파 조사 시 발생되는 방전의 순간 온도가 $5,000 \sim 10,000^{\circ} \mathrm{C}$ 에 이 르며, 이러한 고온은 $\mathrm{GAC}$ 의 구조를 변형 시킬 뿐만 아니라 활성화 된 탄소가 산화될 우려가 높다. 이러한 현상을 파악하기 위해 방전 실험을 실시하여 그 결과 를 Fig. 2에 나타내었다. (A)는 일반 GAC를 마이크로 파 출력을 $500 \mathrm{~W}$ 조사하였을 때 발생되는 방전의 세 기를 나타내었고, $(\mathrm{B})$ 는 $\mathrm{Si} / \mathrm{GAC}$ 의 방전 세기를 나타 내었다. 일반 $\mathrm{GAC}$ 의 경우 마이크로파 조사와 함께 1-6 V의 방전 피크를 확인할 수 있었다. 또한 시간에 따른 방전 피크는 비교적 일정한 경향으로 피크의 높 낮이가 변하는 것을 확인 할 수 있다. 이는 유리전자의 생성과 소멸이 반복적으로 발생하여 이러한 현상이

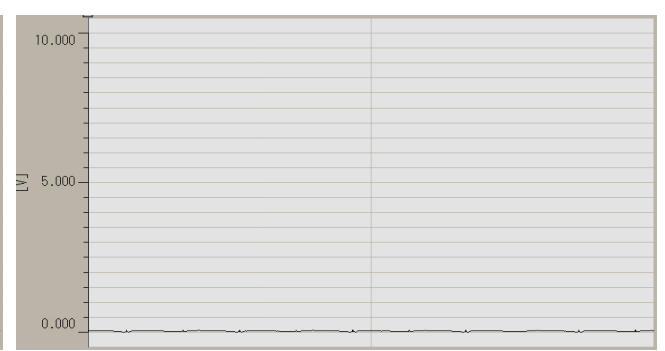

(B)

Fig. 2. Discharge curve under microwave irradiation at $500 \mathrm{~W}(\mathrm{~A}$ : Virgin $\mathrm{GAC}, \mathrm{B}: 5 \mathrm{wt} \% \mathrm{Si} / \mathrm{GAC}, 10 \mathrm{wt} \% \mathrm{Si} / \mathrm{GAC}, 20 \mathrm{wt} \% \mathrm{Si} / \mathrm{GAC})$. 
발생 된 것으로 Jou 등(1998)의 연구와 동일한 결과를 확인하였다. 또한 $\mathrm{Si} / \mathrm{GAC}$ 들은 방전피크가 나타나지 않은 것을 확인 할 수 있다. 이는 규석이 잘 알려진 절 연물이고 $\mathrm{GAC}$ 와 $\mathrm{GAC}$ 사이의 전위차가 야기되었을 때, 전류의 흐름을 차단하여 방전현상을 억제하였다 고 사료된다.

또한 방전 현상이 온도에 미치는 영항을 파악 하기 위해 일반 $\mathrm{GAC}$ 와 $\mathrm{Si} / \mathrm{GAC}$ 의 온도변화를 Fig. 3 에 나타내었다. 각각의 물질의 충진량을 $1 \mathrm{~g}$ 으 로 동일하게 하고 마이크로파 출력을 $100 \mathrm{~W}, 200 \mathrm{~W}$, $300 \mathrm{~W}, 400 \mathrm{~W}$ 로 구분하여 조사 후 1 분대 온도를 확 인하였다. 그 결과 일반 $\mathrm{GAC}$ 의 경우 마이크로파 출력 $100 \mathrm{~W}$ 에서 약 $230^{\circ} \mathrm{C}$ 를 확인하였고 $200 \mathrm{~W}$ 는 약 38 $0^{\circ} \mathrm{C}, 300 \mathrm{~W}$ 는 약 $620^{\circ} \mathrm{C}, 400 \mathrm{~W}$ 는 약 $830^{\circ} \mathrm{C}$ 으로 각각 나타났다. 이는 마이크로파 출력이 $100 \mathrm{~W}$ 에서 400 $\mathrm{W}$ 로 증가함에 따라 방전의 세기 즉, 높은 전위차 가 발생되어 급격한 온도 상승에 기인했을 것이라 사료된다. $\mathrm{Si} / \mathrm{GAC}$ 의 경우 $100 \mathrm{~W}$ 에서는 $80 \sim 86{ }^{\circ} \mathrm{C}$, $200 \mathrm{~W}$ 에서는 122 135 ${ }^{\circ} \mathrm{C}, 300 \mathrm{~W}$ 에서는 280 294 ${ }^{\circ} \mathrm{C}, 400 \mathrm{~W}$ 에서는 $367 \sim 381{ }^{\circ} \mathrm{C}$ 로 온도가 규소의 함량 에 따라 감소하였으며 일반 $\mathrm{GAC}$ 와 $\mathrm{Si} / \mathrm{GAC}$ 의 온도감 소율은 $100 \mathrm{~W}$ 는 약 $31 \%, 200 \mathrm{~W}$ 는 약 $33 \%, 300 \mathrm{~W}$ 는 약 $40 \%, 400 \mathrm{~W}$ 는 약 $42 \%$ 로 나타났다. 온도감소율은 출력증가시 다소 증가하는 경향을 보여 주는데 이는 출력의 증가로 인해 일반 $\mathrm{GAC}$ 와 $\mathrm{Si} / \mathrm{GAC}$ 의 온도폭이 커진 것에 기인한 것으로 사료됩니다. 출력의 증가에 의한 $\mathrm{GAC}$ 의 온도변화 실험결과 $\mathrm{Si} / \mathrm{GAC}$ 의 경우 일반 $\mathrm{GAC}$ 에 비해 급격한 온도상승을 제어하며 규소성분 이 방전효과를 줄이는데 효과적임을 보여주었다.

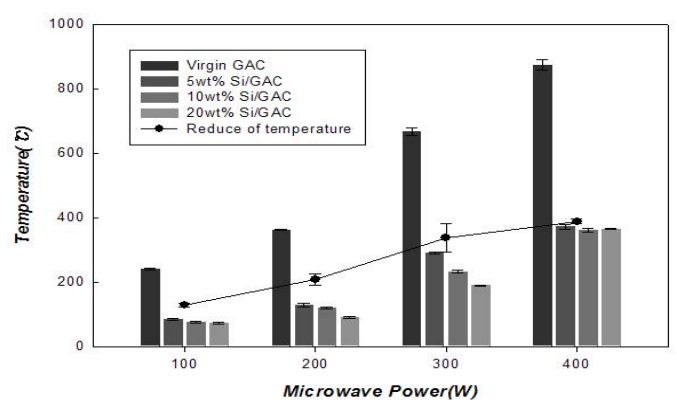

Fig. 3. Temperature variation of GAC by various microwave power.

\section{3. 톨루엔의 흡착 및 탈착}

Fig. 4는 일반 GAC, $5 \mathrm{wt} \%, 10 \mathrm{wt} \%, 20 \mathrm{wt} \% \mathrm{Si} /$ $\mathrm{GAC}$ 별 톨루엔의 흡착 파과곡선을 나타내었다. 그 결 과 일반 $\mathrm{GAC}$ 의 경우 약 27 분대 파과가 시작되었으며, $5 \mathrm{wt} \% \mathrm{Si} / \mathrm{GAC}$ 는 약 23 분, $10 \mathrm{wt} \% \mathrm{Si} / \mathrm{GAC}$ 은 약 16 분, $20 \mathrm{wt} . \% \mathrm{Si} / \mathrm{GAC}$ 약 16 분으로 나타났다. 파과시간대 는 일반 $\mathrm{GAC}$ 에 비해 약 $4 \sim 11$ 분의 차이를 보이고 있 으며, $100 \%$ 파과에 도달된 시간은 $57 \sim 64$ 분으로 나 타났다. 또한 $5 \mathrm{wt} \% \mathrm{Si} / \mathrm{GAC}$ 와 일반 $\mathrm{GAC}$ 의 파과 시 점이 약 4 분대의 차이를 보이고 있어, 다른 $\mathrm{Si} / \mathrm{GAC}$ 에 비해 흡착능이 높은 것으로 나타났다. 이는 물질의 표 면 분석결과에서 보여 준 것 같이 $\mathrm{GAC}$ 표면에 규석을 코팅 하였을 때 비표면적이 감소하는 경향과 같은 결 과를 확인하였다.

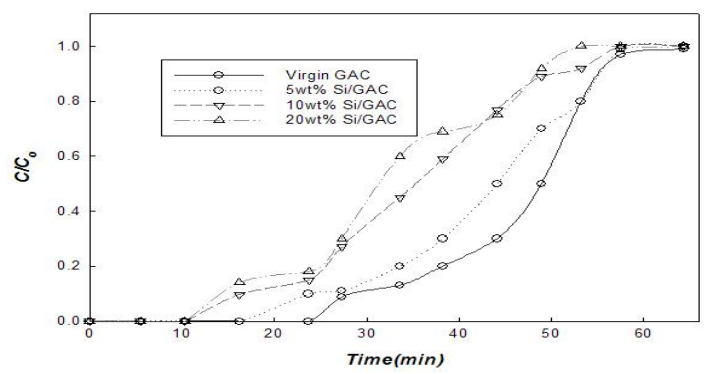

Fig. 4. Breakthrough curve of toluene for $5 \mathrm{wt} \% \mathrm{Si} / \mathrm{GAC}$, $10 \mathrm{wt} \% \mathrm{Si} / \mathrm{GAC}, 20 \mathrm{wt} . \% \mathrm{Si} / \mathrm{GAC}$ and GAC. : C/Co (toluene concentration of outlet/toluene concentration of inlet)

탈착실험은 방전 및 온도실험 결과 톨루엔의 비점 도달에 비교적 적합한 마이크로파 출력을 $300 \mathrm{~W}$ 로 고정하여, 5 분간 4 회 반복 조사하였으며 그 결과를 Fig. 5 에 나타내었다. 우선 1 회 탈착 시 일반 $\mathrm{GAC}$ 의 탈착율은 $90.5 \%$ 로 가장 높았으며, $5 \mathrm{wt} \% \mathrm{Si} / \mathrm{GAC}$ 는 $85.4 \%, 10 \mathrm{wt} \% \mathrm{Si} / \mathrm{GAC}$ 는 $78 \%, 20 \mathrm{wt} \% \mathrm{Si} / \mathrm{GAC}$ 는 $72.5 \%$ 로 나타났고, 2회 탈착율은 $4.35 \sim 5.23 \%$ 을 보 이고 있고, 3 회는 $2.52 \sim 5.46 \%, 4$ 회는 $0.44 \sim 0.56 \%$ 를 확인 하였다. 이들의 총 탈착효율은 일반 $\mathrm{GAC}$ $98.59 \%, 5 \mathrm{wt} \% \mathrm{Si} / \mathrm{GAC} 97.03 \%, 10 \mathrm{wt} \% \mathrm{Si} / \mathrm{GAC}$ $86.03 \% .20 \mathrm{wt} \% \mathrm{Si} / \mathrm{GAC} 84.65 \%$ 로 나타나났다. 흡탈 착 실험 통하여 규석으로 코팅 된 $\mathrm{GAC}$ 중 $5 \mathrm{wt} \%$ $\mathrm{Si} / \mathrm{GAC}$ 는 가장 높은 탈착효율을 확인하였다. $\mathrm{Kuo}(2008)$ 
의 연구를 살펴보면 C.I. Reactive Red 2 solution을 탄 소나노튜브에 흡착하여 $\mathrm{NaOH}$ 와 마이크로파를 이용 한 탈착율을 비교하였는데 $\mathrm{NaOH}$ 로 탈착효율보다 마 이크로파를 이용하였을 때 탈착 효율이 약 $64 \%$ 증가 함을 보여주었다. 또한 Jou 등(1998)은 벤젠, 톨루엔, 자일렌이 흡착된 $\mathrm{GAC}$ 에 마이크로파 출력을 $1000 \mathrm{~W}$ 로 하여 유기물질 제거 실험을 한 결과 마이크로파 조 사 후 약 1 분 동안 약 $98 \%$ 의 제거 효율을 보여주어 마 이크로파가 유기물질의 탈착 및 제거에 유용한 기술 임을 보여주었다.

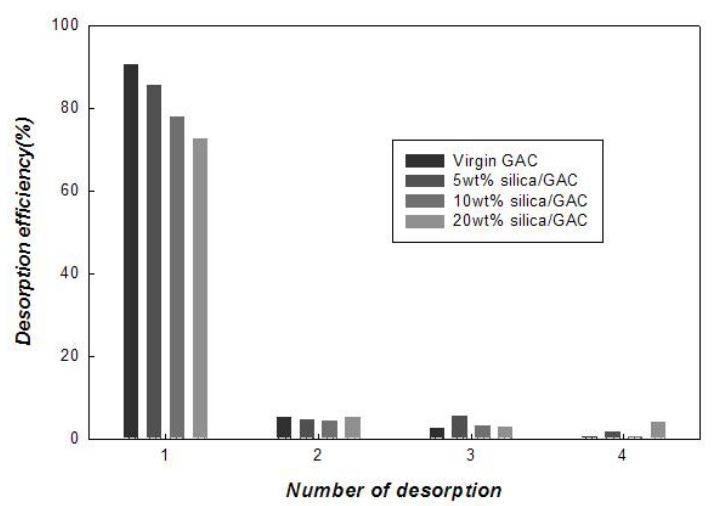

Fig. 5. Desorption efficiency of toluene with four-cycles microwave irradiation.

또한 일반 $\mathrm{GAC}$ 와 $5 \mathrm{wt} \% \mathrm{Si} / \mathrm{GAC}$ 를 마이크로파 조 사에 따른 질량 변화를 Fig. 6에 나타내었다. 이 때 마 이크로파 출력을 $300 \mathrm{~W}$ 로 고정하고, 조사 시간을 5 분 씩 20회 실시 하여 무게 변화를 확인하였다. 그 결과 일반 $\mathrm{GAC}$ 의 무게변화율은 마이크로파를 20 회 조사 하였을 때 약 $2.2 \%$ 로 나타났으며, $5 \mathrm{wt} \% \mathrm{Si} / \mathrm{GAC}$ 의 경우 약 $0.4 \%$ 의 무게변화율로 일반 $\mathrm{GAC}$ 는 $5 \mathrm{wt} \%$ $\mathrm{Si} / \mathrm{GAC}$ 에 비해 약 5.5 배의 무게감소율을 보이고 있 다. 또한 마이크로파 조사 전후의 BET 분석 결과 일 반 $\mathrm{GAC}$ 의 경우 약 $3.41 \%$ 의 표면적 감소를 확인하였 으며, $5 \mathrm{wt} \% \mathrm{Si} / \mathrm{GAC}$ 의 경우 비표면적 감소는 약 $0.1 \%$ 내외로 매우 낮은 결과를 확인하였다. 따라서 GAC 표 면에 절연물질인 규석이 첨가 될 경우 $\mathrm{GAC}$ 의 산화에 따른 비표면적 감소를 줄일 수 있을 것으로 사료된다. 흡탈착 실험 결과 일반 $\mathrm{GAC}$ 의 흡탈착 효율이 $5 \mathrm{wt} \%$ $\mathrm{Si} / \mathrm{GAC}$ 에 비해 다소 높았지만, 일반 $\mathrm{GAC}$ 를 20 회 이
상 재사용 했을 경우 재흡착 효율에 영향을 미칠 것으 로 사료된다.

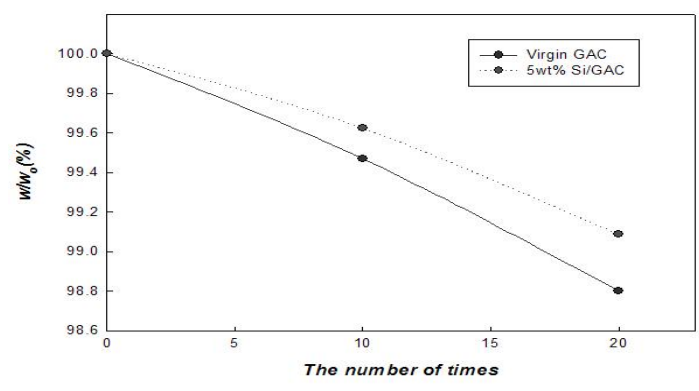

Fig. 6. Weight change curve with microwave irradiation. : W/Wo(\%)(GAC weight after microwave irradiation/ initial GAC weight)

\section{4. 결 론}

본 연구는 열적탈착을 이용한 활성탄의 재생에 관 한 기초연구로 탄소계 물질에 마이크로파 조사 시 나 타나는 아크방전을 방지하고 흡탈착효율 및 내구성평 가를 통해 마이크로파에 가장 적합한 탄소계 흡착제 를 개발하고자 하였으며, 다음과 같은 결과를 도출하 였다.

1) 일반 $\mathrm{GAC}$ 와 $\mathrm{Si} / \mathrm{GAC}$ 의 표면 분석 결과 규석의 함량이 증가 할수록 $\mathrm{GAC}$ 의 표면의 규석의 침착 현상을 SEM을 통해 확인 하였고, BET를 통한 비표면적 분석결과 규석의 함량이 증가 할수록 일반 $\mathrm{GAC}$ 에 비해 $13 \%, 28 \%, 33 \%$ 의 기공의 비 표면적이 감소하는 것을 확인하였다. 비표면적 의 감소는 톨루엔의 흡착에도 영향을 주어 일반 $\mathrm{GAC}$ 에 비해 $\mathrm{Si} / \mathrm{GAC}$ 의 흡착효율이 떨어짐을 확인하였다. 그러나 $5 \mathrm{wt} \% \quad \mathrm{Si} / \mathrm{GAC}$ 가 다른 $\mathrm{Si} / \mathrm{GAC}$ 물질에 비해 흡착효율이 가장 높으며 일 반 $\mathrm{GAC}$ 와 유사한 흡착특성을 보여주었다.

2) 일반 $\mathrm{GAC}$ 와 $\mathrm{Si} / \mathrm{GAC}$ 의 방전 실험결과 마이크 로파 출력 $500 \mathrm{~W}$ 에서 방전의 세기가 $1 \sim 6 \mathrm{~V}$ 의 방전 피크를 확인 하였고, $\mathrm{Si} / \mathrm{GAC}$ 의 경우 방전 현상은 나타지 않음을 확인하였다. 방전 실험결 과를 바탕으로 일반 $\mathrm{GAC}$ 와 $\mathrm{Si} / \mathrm{GAC}$ 의 온도변 
화를 살펴본 결과 $\mathrm{Si} / \mathrm{GAC}$ 의 경우 일반 $\mathrm{GAC}$ 에 비해 약 $120 \sim 500^{\circ} \mathrm{C}$ 정도의 온도감소를 확인 하 였으며, 이는 규석이 방전제어를 통해 급격한 온 도 상승을 낮추는 역할 하였다고 판단된다.

3) 톨루엔의 탈착 실험 결과 일반 $\mathrm{GAC} 98.59 \%$, $5 \mathrm{wt} \% \quad \mathrm{Si} / \mathrm{GAC} \quad 97.03 \%, \quad 10 \mathrm{wt} \% \quad \mathrm{Si} / \mathrm{GAC}$ $86.03 \%, 20 \mathrm{wt} \% \mathrm{Si} / \mathrm{GAC} 84.65 \%$ 의 효율을 확 인하였고 규석으로 코팅 된 $\mathrm{GAC}$ 중 $5 \mathrm{wt} \%$ $\mathrm{Si} / \mathrm{GAC}$ 는 가장 높은 탈착효율을 나타내었다. 또한 마이크로파 조사에 따른 질량 변화를 확인 한 결과, $5 \mathrm{wt} \% \mathrm{Si} / \mathrm{GAC}$ 에 비해 일반 $\mathrm{GAC}$ 의 무 게감소가 5.5 배 더 크며, 비표면적은 약 $3.41 \%$ 감소하였다. 일반 $\mathrm{GAC}$ 를 고온에서 연속 사용 시 재생 효율에 영향을 줄 것으로 사료된다.

본 연구결과 $\mathrm{Si} / \mathrm{GAC}$ 는 일반 $\mathrm{GAC}$ 에 비해 흡착효 율이 다소 떨어지는 것을 확인하였다. 그러나 마이크 로파를 톨루엔의 탈착에 이용할 경우 방전 및 급격한 온도 상승을 차단하는 장점을 확인하였다. 특히 $5 \mathrm{wt} \%$ $\mathrm{Si} / \mathrm{GAC}$ 는 아크방전의 영향이 적고, 일반 활성탄과 유 사한 흡탈착율을 보이고 있어 마이크로파를 이용한 톨루엔 탈착 및 활성탄의 재생에서 가장 적합한 흡착 제임을 보여주었다. 이를 기초로 마이크로파를 이용 한 활성탄 재생연구가 추가적으로 수행되어야 할 것 으로 사료된다.

\section{참 고 문 헌}

류영기, 노덕수, 이창하, 1998 , 초임계 이산화탄소에 의한 활성탄소섬유로부터 $\mathrm{MEK}$ 와 톨루엔의 탈 착 특성, 한국화학공학회. 1, 56-61.

임선기, 2003, VOC저감에 대한 배출방지 기술 및 대체 기술, 정밀화학, 69, 25-32.

Aktas, O., Cecen, F., 2007, Adsorption, desorption and bioregeneration in the treatment of 2-chlorophenols with activated carbon, J. Hazard. Mater., 141, 769-777.

Alvarez, P. M., Beltran, F. J., Gomez-Serrano, V., Jaramillo, J., Rodriguez, E. M., 2004, Comparison between thermal and ozone regenerations of spent activated carbon exhausted with phenol, Water Res, 38, 2155-2165.

Ania, C. O., Menendez, J. A., Parra, J. B., Pis, J. J., 2004, Microwave-induced regeneration of activated carbons polluted with phenol, A comparison with conventional thermal regeneration, Carbon, 42, 1383-1387.

Cid, B. P., Alborés, A. F., Gómez, E. F., López, E. F., 2001, Use of microwave single extractions for metal fractionation in sewage sludge samples, Anal. Chim. Acta, 431, 209-218.

Fang, C. S., Lai, P. M. C., 1996, Microwave regeneration of spent powder activated carbon, Chem. Eng. Commun., 147, 17-27.

Hernandez, M. T., Gonzalez, M., 2002, Synthesis of resins as alpha-alumina precursors by the Pechini method using microwave and infrared heating, J. Eur. Ceram. Soc., 22(16), 2861-2868.

Horng, R. S., Tseng, I. C., 2008, Regeneration of granular activated carbon saturated with acetone and isopropyl alcohol via a recirculation process under $\mathrm{H}_{2} \mathrm{O}_{2} / \mathrm{UV}$ oxidation, J. Hazard. Mater., 154, 366-372.

Jou, C., 1998, Application of activated carbon in a microwave radiation field to treat trichloroethylene, Carbon, 36(11), 1643-1648.

Jou, C. J. G., Tai, H. S., 1998, Application of granular activated carbon packed-bed reactor in microwave radiation field to treat $\mathrm{BTX}$, Chemosphere, 37, 685-698.

Kong, Y., Cha, C. Y., 1995, Microwave-induced regeneration of NOx-saturated char, Energ. Fuel., 6, 1245-1249.

Kuo, C. Y., 2008, Desorption and re-adsorption of carbon nanotubes: Comparisons of sodium hydroxide and microwave irradiation processes, J. Hazard. Mater., 152, 949-954.

Lim, J. L., Okada, M., 2005. Regeneration of granular activated carbon using ultrasound, Ultrason. Sonochem., 12, 277-282.

Liu, X., Yu, G., Han, W., 2007, Granular activated carbon adsorption and microwave regeneration for the treatment of 2,4,5-trichlorobiphenyl in simulated soil-washing solution, J. Hazard. Mater., 147, 746-751. 
Lu, A., Zhang, S., Shan, X., Wang, S., Wang, Z., 2003, Application of microwave extraction for the evaluation of bioavailability of rare earth elements in soils, Chemosphere, 53, 1067-1075.

Nakano, Y., Hua, L. Q., Nishijima, W., Shoto, E., Okada, M., 2000, Biodegradation of trichloroethylene
(TCE) adsorbed on granular activated carbon (GAC), Water Res., 34, 4139-4142.

Zong, L., Zhou, S., Sgriccia, N, Hawley, M. C., Kempel, L. C., 2003, A review of microwave-assisted polymer chemistry(MAPC), J. Microwave Power E.E., 38(1), 49-74. 